\title{
Enhancing Learning Experiences of Graduate Students in the Faculty of Engineering and Applied Sciences at Memorial University of Newfoundland
}

\author{
Susan Caines and Leonard Lye \\ Memorial University of Newfoundland \\ susan.caines@mun.ca
}

\begin{abstract}
The Faculty of Engineering and Applied Science (FEAS) at Memorial University of Newfoundland (MUN) offer 17 unique programs to over 500 graduate students. In addition to providing financial support, office space, courses, and supervision to students, FEAS has developed an interconnected series of programs, seminars, and workshops to help graduate students succeed in their studies, research, and life after graduation. Among these are the Graduate Seminar Course, the TA Training Program, the Outstanding TA Award, regular professional development seminars, the Graduate Mentorship Program, in addition to numerous EDGE (Enhanced Development of the Graduate Experience) programs and workshops offered by the School of Graduate Studies. This suite of academic and professional supports plays a critical role in FEAS's goals and represent innovative and significant work that foster graduate student success. This paper describes these innovative strategies and demonstrates FEAS's and MUN's commitment to providing outstanding opportunities for students to grow and succeed in their graduate studies.
\end{abstract}

Keywords: Graduate Studies, Enhancing Education, Academic Support, Professional Support.

\section{INTRODUCTION}

The Faculty of Engineering and Applied Science (FEAS) at Memorial University of Newfoundland (MUN) began offering graduate programs in 1970. Graduate enrolment and the number of programs offered by FEAS have grown significantly over the last 44 years. The number of graduating students has also increased, from a total of 100 students before 1985 , to a current average of 60 students a year. Enrolment has tripled over the last 10 years from 157 in 2004 to 550 in 2014. The graduate programs FEAS offers have also become more diverse. Prior to 1990, there were only one PhD and four Masters Programs. Currently, FEAS offers a total of 17 unique programs (6 PhD, 6 MEng, 3 MASc, MEM, and a Graduate Diploma). The MASc, MEM, and Graduate Diploma programs are course-based while the PhD and MEng programs are research-based.

By 2020, the projected enrolment in all of these programs is expected to be 700 graduate students. This growth is mandated by MUN's Enrolment Plan and FEAS 2020 Vision to grow research and teaching capacity in areas of strategic importance. To ensure this growth is sustainable and meaningful, and in addition to providing financial support, office space, courses, and supervision to students, FEAS has developed an interconnected series of programs and workshops to help graduate students succeed in their studies, research, and life after graduation. Among these are the Graduate Seminar Course, the TA Training Program, the Outstanding TA Award, regular seminars for graduate students, and the Graduate Mentorship Program. This suite of academic and professional supports plays a critical role in FEAS broad goals and represent innovative and significant work that foster graduate student success.

\section{ENHANCED PROGRAMS}

FEAS developed the interconnected series of programs for graduate students to ensure graduates from the program have not only the technical skills to succeed in their work but also the non-technical skills that will ensure smooth transition to the workplace.

This series developed over time with the goal of enhancing and improving the graduate experience for the student while at FEAS and also to develop more prepared and well-rounded engineering professionals upon graduation.

All elements of the series are designed to provide specific information and experiences however communication, Leadership and teamwork, teaching 
and knowledge transfer, and Ethics are common to all. These non-technical skills are identified by Engineers Canada in consultation with industry partners as important workplace skills and are key to undergraduate accreditation [2]

Without enhanced programming, graduate students may not be given formal opportunities to practice and learn these important skills. These nontechnical skills are key to gaining employment and for continued success in the graduates' career $[3,6,7,8$, 9]. In the 2008, Canadian Association for Graduate Studies (CAGS) discussion paper "Professional Skills Development for Graduate Students"[1], four nontechnical skills were identified as important for graduate student success. These skills are:

1. Communication

2. Management

3. Teaching and Knowledge transfer

4. Ethics

In 2007 Memorial University developed the Enhanced Development of the Graduate Experience (EDGE) program to formally address some of these skills [4]. This program is available to all graduate students at MUN and includes programming for:

- $\quad$ Leadership and management

- Communication and interpersonal skills

- Critical and creative thinking

- Integrity and ethics

- Global and intercultural awareness

- Teaching skills

- Societal and civic responsibility

- Career development

- Research

While these activities are beneficial to all graduate students, a complementary and more targeted program was developed to address specific skills needed in the Engineering Profession.

The integrated engineering program developed into 5 key programs to enhance engineering graduate students' skills in communication, management (leadership and teamwork), teaching and knowledge transfer, and ethics.

\subsection{Graduate Seminar Course}

This credit course was developed as an introduction to graduate studies at MUN and is required for all new Masters Students in a researchbased program. While not required, $\mathrm{PhD}$ students are also encouraged to attend the course. The Graduate Seminar Course plays a significant role in helping students understand expectations of graduate work, develop important skills required to be successful students, and make all graduate students aware of the important regulations and policies.

Communication skills are enhances through this course. Sessions on presentations and public speaking are given and the students are required to present three times during the course. First a 1 minute introduction presentation is done, the a 3 minute technical overview of their research (similar to the 3 minute thesis competition) is presented to the class. Finally, a Graduate Student Symposium is held at the end of the course following a format similar to technical conferences. During the symposium, every student delivers a formal 20 minute presentation on a technical topic related to his or her research.

Leadership and teamwork are discussed in the course formally in sessions on dealing with conflict and the responsibility of the engineering profession. Informally, the course gives students an opportunity to meet their peers and begin networking, integrating into the university community, developing research groups and leading group discussions.

Teaching and knowledge transfer is developed through discussions with library professionals where students are introduced to library resources, discuss issues of plagiarism and intellectual property (IP). A panel discussion with experienced supervisors on general practices of performing research is conducted where students and supervisors engage in an open discussion of research practices and the complex student supervisor relationship.

Ethics is discussed throughout the course and activities. It is presented in the context of the responsibility of professional engineers and the responsibilities of engineering researchers.

\subsection{Teaching Assistant Training Program}

Teaching assistantships provide graduate students an opportunity to develop important technical and communication skills and to contribute to engineering education at all levels. As part of the qualification program for new teaching assistants (TA), FEAS offers an innovative one-day intensive program that introduces students to the roles and responsibilities of a TA position. The Engineering TA Training Program (ENGTATP) gives new TAs an introduction to the activities expected in the FEAS, from marking assignments and papers to running tutorials and lecturing. The training also outlines university policies including academic misconduct, plagiarism, privacy, and harassment. To help new students succeed in their first TA assignment, the training 
includes discussions that help develop the nontechnical skills needed for future success.

The ENGTATP is facilitated by the Associate Dean of Graduate Studies and two experienced TAs. The intent of this diversity in facilitators is to bring different perspectives to the new TAs and to encourage an open discussion. This training program has been in place since 2011 and is provided once a semester ( 3 times a year to a total of about 80 new research graduate students). To provide continuing support to the new TAs, a web-based TA Toolbox was designed. The TA Toolbox is located in Memorial's Desire2learn (D2L) system. Site access is limited to graduate students who have completed the TA training and contains the course information as well as additional documents and links to support continued learning. A discussion forum called TA Talk is also used to answer questions and provide guidance when needed in an informal manner.

Communication skills are developed during the course through lessons on communicating in the classroom, and with professors, and tips on dealing with problems.

Leadership and teamwork skills are practiced during course activities. Students participate in small group activities where they discuss attributes of effective TAs, discuss and analyses situational case studies, and through a practice lab sessions where students visit laboratory facilities and participate in a "what-to-do-for-your-first-lab" demonstration.

Teaching and knowledge transfer is the focus of the day. Strategies for classroom etiquette, active learning, and communicating with different types of students are introduced. An open Q\&A is held after the formal lessons and the training concludes with an awards ceremony. Students each receive a manual with additional, in-depth information for future reference.

\subsection{Regular seminars for graduate students}

To support graduate student development throughout their program, regular seminars are available to all graduate students. The Engineering Graduate Student Society (EGSS), together with the Associate Dean (Graduate Studies) office, organize regular seminars each semester that are significant and meaningful for their studies, research, and professional plans.

These seminars are open to all graduate students and are well attended and highly rated. The variety of discussion a topic helps graduate students throughout their time at MUN and gives them insight into their changing roles from new graduate student to successful graduate.
Seminars are given by a variety of invited guests and contribute to the development of non-technical professional skills. These sessions include but are not limited to:

\section{Communication}

- Preparing for the Comprehensive Exam

- Preparing and delivering effective Presentations

- Writing Engineering Literature reviews

- Guide to thesis writing

Leadership and teamwork

- Recognizing and dealing with mental health issues

- The Entrepreneurship Training Program for graduate students

Teaching and knowledge transfer

- How to be academically successful

- MITACS: Funding for internships and skill development for future career

\subsection{Graduate Mentorship Program}

The Graduate Mentorship Program (GMP) was established by FEAS as an innovative bridge between technical knowledge and the work force by introducing engineering graduate students to business leaders with the goal of developing business acumen in the students. For the pilot program in 2014, FEAS accepted 10 students and matched them to mentors based on common professional and academic interests. Questions like "What are you career goals for the next five years?" and "What do you feel you can give to the program?" helped the selection committee identify students that would benefit most from the new program.

The GMP program included one speed-networking event, where the 10 students had the opportunity to ask 10 business leaders what skills and strategies they used in their careers to be successful. The 10 business leaders were all drawn from the network of the facilitator, Ms. Carol Bartlett, a prominent local business leader. The 10 mentors are either CEOs or Vice-Presidents of large local companies or international corporations. The students were also invited to a networking event organized by the Newfoundland and Labrador Oil and Gas Industries Association to meet other business leaders and players in one of Newfoundland's major industry. Most of the students prepared business cards for the event and exchanged them with new contacts.

As part of the ongoing program, the mentors and the students pick the top three people they would like to be paired with for the program and FEAS makes the best matches. After the initial event, the mentors meet with the students once per month for a three- 
month period. If the mentor feels that it is appropriate, they ask the student to sit in on a business meeting for the final activity. The program facilitator also meets with the students each month to discuss strategies to build business skills with and without having a job and to facilitate a discussion of the lessons they are learning from the program.

Students from the program have been extremely grateful for the opportunity and feedback from both the students and the mentors is exceptionally positive. Several students have noted this is a life-changing experience Collins Nana Obeng describes the program as "... overwhelmingly positive. I have been amazed by the leaps in my social and developmental growth since my first interaction with all the exceptional mentors. I believe my life has been enriched with this amazing experience and will go forward into my career with all the skills and lessons learned to be a successful and well-rounded Engineer."

The Faculty notes a remarkable difference in the students' confidence and their approach to their careers. FEAS expanded the program in 2015 to include 12 students and mentors.

This program focuses on Leadership and teamwork and gives the graduate student a unique opportunity to interact and learn from successful professionals and to develop their own professional skills.

\subsection{Outstanding TA Award}

Recognizing graduate students for their efforts is important to keeping students motivated in their program and to encourage other students to strive for excellence in their university contributions. One way the FEAS recognizes excellence is through its Outstanding TA Award. Nomination for this annual award can be made by course instructors and/or undergraduate students, and up to 5 exceptional TAs are awarded $\$ 300$ and a recognition certificate after the winter semester. Started in 2012-13, this award is based on a teaching dossier, student evaluations about the TA, letters of support from instructors, technicians, and/or students, and any other evidence of outstanding performance provided by the nominee. About 20 nominations are submitted each year for these awards, a reflection of the high-quality teaching offered by graduate students as well as the success of ENGTATP.

Communication, Leadership and teamwork and Teaching and knowledge transfer are vital skills to being an outstanding TA and this award recognizes students for their success.

\section{DISCUSSION}

The enhanced learning experience program successfully teaches students non-technical skills through specific activities and lectures. Communication, Leadership and teamwork, and Teaching and knowledge transfer are well covered in the current programming. Ethics, while generally discussed and expected in all activities is, there is limited formal ethics education for graduate students. Ethics programming can be included in the TA training program by including ethical theory and case studies in the program and manual. Online resources can be added to the TA Toolbox. Sessions on the ethics of research, ethical decision making, and the responsibility of professional practice can be added as standalone seminars for graduate students. While ethics is informally covered in the Mentorship program, a more formal session can be introduced to encourage open discussion with professionals and introduce students to real word application of ethical decision-making.

\section{CONCLUSION}

From introducing students to graduate work and resources with the graduate seminar course, through TA training and continued diverse seminars as they progress in their program, to preparing them for the workplace with mentorship programs and skills development seminars, MUN FEAS demonstrates its commitment to providing new and innovative opportunities to graduate students.

These programs help develop graduate students skills in communication, leadership and teamwork, Teaching and knowledge transfer, and ethics. Programming modifications are needed to improve the presentation of ethics. Additions to the graduate seminar course, seminar series, and mentorship program will strengthen the ethical knowledge of graduate students at Memorial University's Faculty of Engineering.

These initiatives reflect innovative and significant work that allows MUN FEAS to continue developing graduate students into excellent and meaningful assets to the engineering workplace and fulfill broad institutional goals for teaching and research.

\section{Acknowledgements}

The authors would like to thank Andrew Kim, Director, Graduate Enrolment Services at Memorial University's School of Graduate Studies for his contribution to the development of this program. 


\section{References}

[1]CAGS. (2008). "Professional Skills Development for Graduate Students", http://www.cags.ca, 2013

[2] Engineers Canada, Canadian Engineering Accreditation Board, "2010 Accreditation Criteria and Procedures", www.engineerscanada.ca, 2010.

[3]McMenemy, K. \& Ferguson, S. 2009, "Enhancing the teaching of professional practice and key skills in engineering through the use of computer animation", International Journal of Electrical Engineering Education, vol. 46, no. 2, pp. 164.

[4] MUN, "Enhanced Development of the Graduate Experience (EDGE)" http://www.mun.ca/sgs/edge.php, 2015

CEEA15; Paper 071

McMaster University; May 31 - June 3, 2015

-5 of $5-$
[5] MUN, "Graduate Mentorship Program"

http://www.engr.mun.ca/graduate/mentor_ship.php. 2015

[6] Pence, K.R. \& Rowe, C.J. 2012, "Enhancing

Engineering Education through Engineering Management", Journal of STEM Education : Innovations and Research, vol. 13 , no. 3 , pp. $46-51$.

[7] Rao, M.S. 2014, "Enhancing employability in engineering and management students through soft skills", Industrial and Commercial Training, vol. 46, no. 1, pp. 4248.

[8] Rose, M (2012), “Graduate Student Professional Development: A Survey with Recommendations". http://www.cags.ca, 2013

[9] Woolfrey-Fahey, S. 2013, "Preparing for life after graduate school", Gazette, Oct 9 ,pp 9 